\title{
Analysis on the Applicability of Phase Selection Components of Inverter Power Supply Transmission Line
}

\author{
Xu Shuo ${ }^{*}$, Yang Bingyuan, and Li Dongsheng \\ School of Inner Mongolia University of Technology, Hohhot, China
}

\begin{abstract}
This article analyzes the applicability of AC line phase selection components in the context of large-scale offshore wind farms through multi-terminal flexible direct transmission. When the AC line fails, the converter station adopts a control strategy to suppress negative sequence and only outputs positive sequence current, resulting The positive and negative sequence current distribution coefficients on the converter station side are seriously unequal; This leads to adaptability problems of traditional protection phase selection components, which may cause incorrect actions of reclosing, protection ranging and distance protection. The simulation results based on RTDS verify the correctness of the theoretical analysis.
\end{abstract}

Keywords: phase selection components; control strategy; RTDS

\section{Introduction}

The uneven distribution of energy in my country makes AC/DC hybrid power grids have good development prospects. Multi-Terminal Direct Current based on Modular Multilevel Converter (MMC-MTDC) also has the technical advantages of MMC high voltage and large capacity, and the flexibility and reliability of MTDC system The operating characteristics of flexibility and economy will be widely used in the connection of new energy grid-connected ${ }^{[1]}$. The centralized delivery of large-scale new energy has become an inevitable trend. Therefore, the correct action of the transmission line protection is of great significance to the safe operation of the MMC-MTDC system. For example, when suppression of negative sequence current is used as the control target of the grid-connected inverter, there is no negative sequence current or very little negative sequence current in the fault current on the converter station side, which will affect the phase selection components of line protection ${ }^{[2]}$. It may cause risks such as wrong protection phase selection, and then affect important functions such as reclosing and protection ranging ${ }^{[3]}$.

*Corresponding author: 632582296@qq.com 


\section{Control strategy of MMC}

The basic structure of the MMC-MTDC system with large-scale wind farms is shown in Figure 1. In this system, a wind farm side converter station (WFMMC) with constant AC voltage and constant frequency control is used to gather the output power of the wind farm and incorporate it DC system; the grid-side converter station is used to connect to the AC power grid, in which the side with constant DC voltage control is the master station (GMMC1); the side with constant active and reactive power control is the slave station (GMMC2). In case of AC line fault, MMC adopts the control strategy of restraining negative sequence component and limiting amplitude, so that the negative sequence component of fault current is 0 and the amplitude of fault current is $1.1 \mathrm{pu}$ of rated current ${ }^{[4]}$.

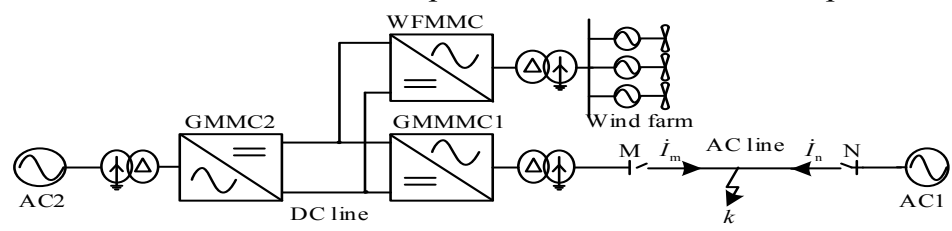

Figure 1. Structure diagram of MMC-MTDC simulation system

\section{Impact on phase selection component}

\subsection{Phase Selection Based On Variation Components}

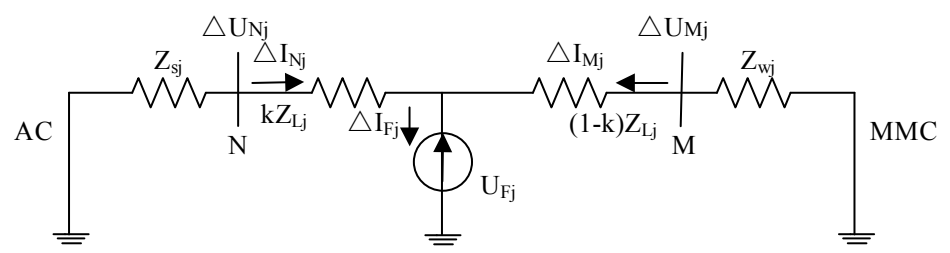

Figure 2. Additional state equivalent diagram of transmission line fault

The phase current difference mutation amount phase selection component is the component that judges the fault phase by comparing the relationship between the amplitude of the phase current difference mutation amount between two phases, and it can be expressed as

$$
\left\{\begin{array}{l}
\Delta \dot{I}_{\mathrm{ab}}=\left(\dot{I}_{\mathrm{a}}-\dot{I}_{\mathrm{b}}\right)-\left(\dot{I}_{\mathrm{a}}{ }^{[0]}-\dot{I}_{\mathrm{b}}{ }^{[0]}\right) \\
\Delta \dot{I}_{\mathrm{bc}}=\left(\dot{I}_{\mathrm{b}}-\dot{I}_{\mathrm{c}}\right)-\left(\dot{I}_{\mathrm{b}}{ }^{[0]}-\dot{I}_{\mathrm{c}}{ }^{[0]}\right)(1) \\
\Delta \dot{I}_{\mathrm{ca}}=\left(\dot{I}_{\mathrm{c}}-\dot{I}_{\mathrm{a}}\right)-\left(\dot{I}_{\mathrm{c}}^{[0]}-\dot{I}_{\mathrm{a}}{ }^{[0]}\right)
\end{array}\right.
$$

where $\Delta \dot{I}_{\mathrm{ab}}$ is change of phase current difference, $\dot{I}_{\varphi}$ and $\dot{I}_{\varphi}{ }^{[0]}$ are phase current after and before the fault. $\varphi=a, b, c$.

There are the following relationships in Figure 2

$$
\left\{\begin{array}{l}
\Delta \dot{I}_{\mathrm{M} 1}=C_{\mathrm{M} 1} \Delta \dot{I}_{\mathrm{F} 1} \\
\dot{I}_{\mathrm{M} 2}=C_{\mathrm{M} 2} \dot{I}_{\mathrm{F} 2} \\
\dot{I}_{\mathrm{M} 0}=C_{\mathrm{M} 0} \dot{I}_{\mathrm{F} 0}
\end{array}\right.
$$


Where $C_{\mathrm{M} 1}, C_{\mathrm{M} 2}, C_{\mathrm{M} 0}$ are current distribution coefficient for positive sequence, negative sequence and zero sequence.

$$
\left\{\begin{array}{l}
C_{\mathrm{M} 1}=\frac{Z_{\mathrm{S} 1}+(1-n) Z_{\mathrm{L} 1}}{Z_{\mathrm{S} 1}+Z_{\mathrm{L} 1}+Z_{\mathrm{W} 1}} \\
C_{\mathrm{M} 2}=\frac{Z_{\mathrm{S} 2}+(1-n) Z_{\mathrm{L} 2}}{Z_{\mathrm{S} 2}+Z_{\mathrm{L} 2}+Z_{\mathrm{W} 2}}(3) \\
C_{\mathrm{M} 0}=\frac{Z_{\mathrm{S} 0}+(1-n) Z_{\mathrm{L} 0}}{Z_{\mathrm{S} 0}+Z_{\mathrm{L} 0}+Z_{\mathrm{T}}}
\end{array}\right.
$$

Where $Z_{\mathrm{S} 1,2,0}$ and $Z_{\mathrm{L} 1,2,0}$ are sequence impedance of the system and the transmission line. $Z_{\mathrm{T}}$ is transformer equivalent impedance. $Z_{\mathrm{w} 1,2}$ is the equivalent sequence impedance of MMC.

When the line fails, the abrupt changes of the phase current difference at the protection can be expressed as follows:

$$
\left\{\begin{array}{l}
\Delta \dot{I}_{\mathrm{ab}}=\left(1-a^{2}\right) \mathrm{C}_{\mathrm{M} 1} \Delta \dot{I}_{\mathrm{F} 1}+(1-a) \mathrm{C}_{\mathrm{M} 2} \Delta \dot{I}_{\mathrm{F} 2} \\
\Delta \dot{I}_{\mathrm{bc}}=\left(a^{2}-a\right) \mathrm{C}_{\mathrm{M} 1} \Delta \dot{I}_{\mathrm{F} 1}+\left(a-a^{2}\right) \mathrm{C}_{\mathrm{M} 2} \Delta \dot{I}_{\mathrm{F} 2}(4) \\
\Delta \dot{I}_{\mathrm{ca}}=(a-1) \mathrm{C}_{\mathrm{M} 1} \Delta \dot{I}_{\mathrm{F} 1}+\left(a^{2}-1\right) \mathrm{C}_{\mathrm{M} 2} \Delta \dot{I}_{\mathrm{F} 2}
\end{array}\right.
$$

Where $a=e^{j 120^{\circ}}, \mathrm{C}_{\mathrm{M} 2}$ is equal to 0 when suppressing negative sequence current. Hence, the abrupt changes of the phase current difference at the protection can be written as:

$$
\left|\Delta \dot{I}_{A B}\right|=\left|\Delta \dot{I}_{B C}\right|=\left|\Delta \dot{I}_{C A}\right|=\sqrt{3}\left|\mathrm{C}_{\mathrm{M} 1} \Delta \dot{I}_{F 1}\right|(5)
$$

At this time, the amount of sudden change in the current difference of each phase is equal, and the phase selection element on the MMC side will select the phase by mistake.

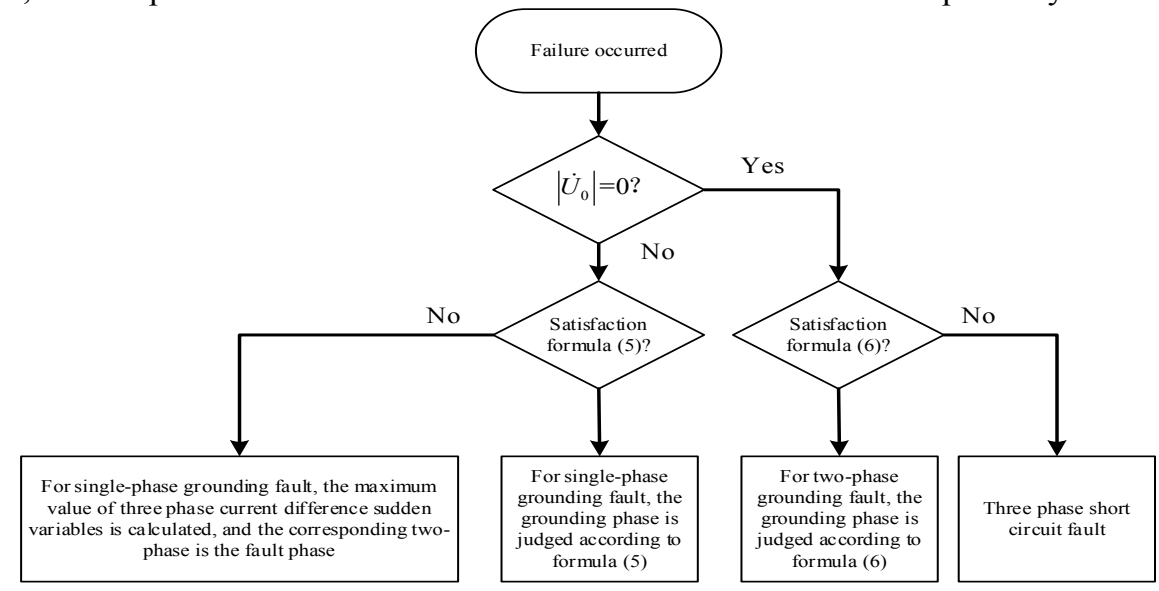

Figure 3. Phase Selection Based On Variation Components 


$$
\begin{aligned}
& \left\{\begin{array}{l}
\left(m\left|\Delta \dot{I}_{\mathrm{BC}}\right| \leq\left|\Delta \dot{I}_{\mathrm{AB}}\right|\right) \&\left(m\left|\Delta \dot{I}_{\mathrm{BC}}\right| \leq\left|\Delta \dot{I}_{\mathrm{CA}}\right|\right) \quad \mathrm{AG} \\
\left(m\left|\Delta \dot{I}_{\mathrm{CA}}\right| \leq\left|\Delta \dot{I}_{\mathrm{AB}}\right|\right) \&\left(m\left|\Delta \dot{I}_{\mathrm{CA}}\right| \leq\left|\Delta \dot{I}_{\mathrm{BC}}\right|\right) \quad \mathrm{BG}(6) \\
\left(m\left|\Delta \dot{I}_{\mathrm{AB}}\right| \leq\left|\Delta \dot{I}_{\mathrm{BC}}\right|\right) \&\left(m\left|\Delta \dot{I}_{\mathrm{AB}}\right| \leq\left|\Delta \dot{I}_{\mathrm{CA}}\right|\right) \quad \mathrm{CG}
\end{array}\right. \\
& \left\{\begin{array}{l}
\left(m\left|\Delta \dot{I}_{\mathrm{C}}\right| \leq\left|\Delta \dot{I}_{\mathrm{A}}\right|\right) \&\left(m\left|\Delta \dot{I}_{\mathrm{C}}\right| \leq\left|\Delta \dot{I}_{\mathrm{B}}\right|\right) \quad \mathrm{ABG} \\
\left(m\left|\Delta \dot{I}_{\mathrm{A}}\right| \leq\left|\Delta \dot{I}_{\mathrm{B}}\right|\right) \&\left(m\left|\Delta \dot{I}_{\mathrm{A}}\right| \leq\left|\Delta \dot{I}_{\mathrm{C}}\right|\right) \quad \mathrm{BCG}(7) \\
\left(m\left|\Delta \dot{I}_{\mathrm{B}}\right| \leq\left|\Delta \dot{I}_{\mathrm{A}}\right|\right) \&\left(m\left|\Delta \dot{I}_{\mathrm{B}}\right| \leq\left|\Delta \dot{I}_{\mathrm{C}}\right|\right) \quad \mathrm{CAG}
\end{array}\right.
\end{aligned}
$$

\subsection{Phase Selection Based On Sequence Components}

This method realizes phase selection by comparing the phase and amplitude relationship between the sequence components of the fault current at the protection installation. It can be accurate by extracting the phase difference between the zero sequence current and the negative sequence current and combining the phase difference between the positive sequence current and the negative sequence current. Determine the fault phase. The phase difference of each sequence current under various asymmetric faults can be expressed as follows:

$$
\left\{\begin{array}{l}
\operatorname{phase} 1=\arg \left(\dot{I}_{\mathrm{a} 0} / \dot{I}_{\mathrm{a} 2}\right) \\
\operatorname{phase} 2=\arg \left(\Delta \dot{I}_{\mathrm{a} 1} / \dot{I}_{\mathrm{a} 2}\right)
\end{array}\right.
$$

When the MMC adopts the control strategy of suppressing the negative sequence current, the negative sequence current in the fault current sent by the MMC side is almost zero. Taking into account the influence of noise and measurement error in the signal sampling process, the actual negative sequence measured by the phase selection element on the straight side The sequence current fault component is a small current signal with random phase, and the phase selection element on the MMC side will select the phase by mistake. The phase selection flowchart of the current sequence component phase selection component is shown in Figures 4 and 5.

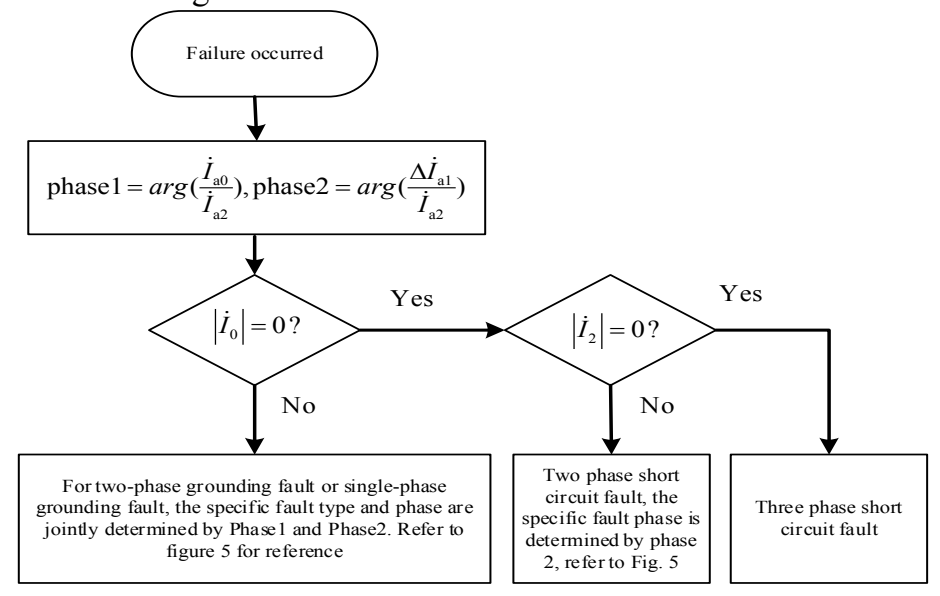

Figure 4. Phase Selection Based On Sequence Components 


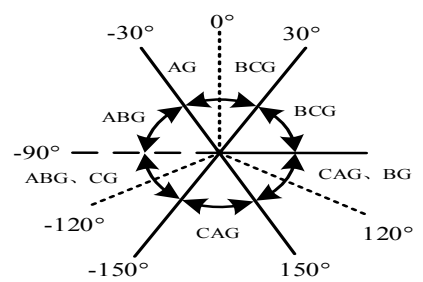

(a) Partition according to Phase 1

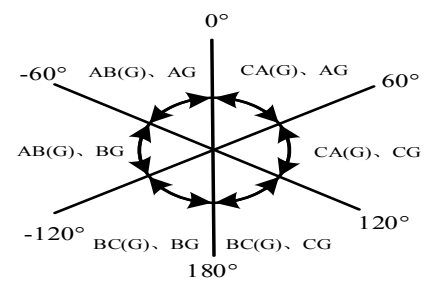

(b) Partition according to Phase2

Figure 5. Fault partitions of two sequence component phase selectors

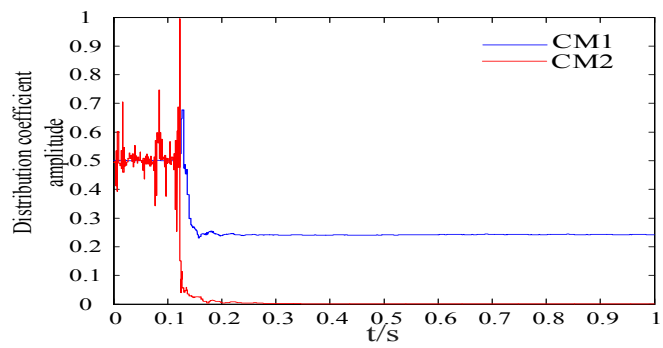

(a) Sequence current distribution coefficient

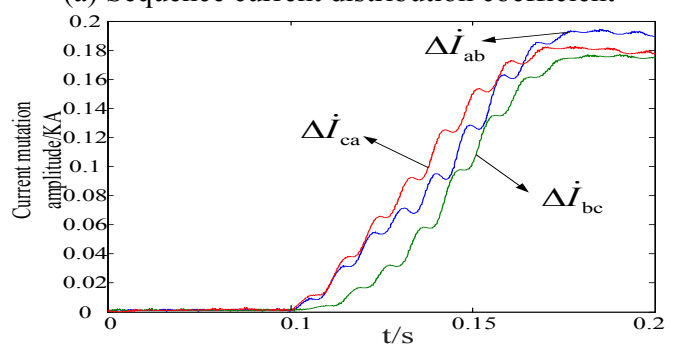

(b) Amplitude of sudden change

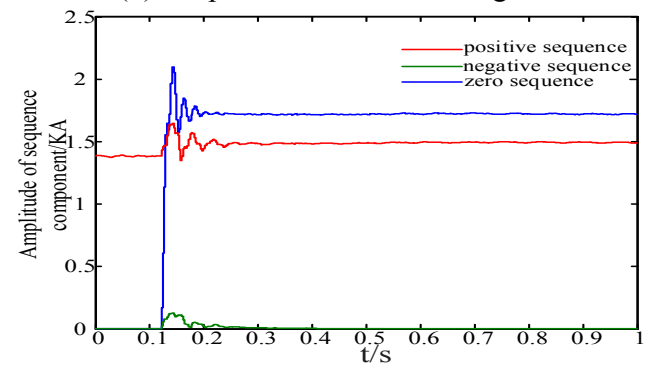

(c) Amplitude of sequence current

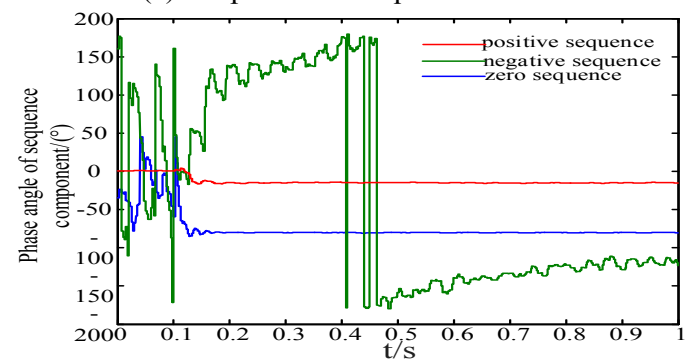

(d) Phase angle of sequence current

Figure 6. RTDS simulation results 


\section{RTDS simulation analysis}

It can be seen from Figure 6 that the negative sequence current control makes the negative sequence current almost 0 at the time of the fault, so the negative sequence current distribution coefficient tends to 0 , which in turn leads to the sudden change of the phase current difference amplitude $\mathrm{A}, \mathrm{B}$ and $\mathrm{C}$ are almost equal, and the simulation results are consistent with the theoretical analysis; the phase of the negative sequence current varies irregularly between $-180^{\circ} \sim 180^{\circ}$ due to the small or no negative sequence content in the fault current, which is determined by the formula (7) The determined current sequence component phase selection element cannot operate correctly. The limiter control makes the positive sequence current amplitude not much different from the normal operating value when the fault occurs. Therefore, the back-side flexible straight system exhibits strong weak feed, and the positive sequence current distribution coefficient is small; because the impedance of the connected transformer is smaller than the back The positive sequence impedance of the side-flexible system causes the zero sequence component of the fault current to be greater than the positive sequence component. The phase selection results of Phase Selection Based On Variation Components and Phase Selection Based On Sequence Components under various fault conditions are given below.

Table 1. Phase selection results of phase selection components under each fault type at point $\mathrm{k}$

\begin{tabular}{|c|c|c|}
\hline Fault type & $\begin{array}{c}\text { Phase Selection Based On } \\
\text { Variation Components }\end{array}$ & $\begin{array}{c}\text { Phase Selection Based On } \\
\text { Sequence Components }\end{array}$ \\
\hline $\mathrm{AG}$ & $\mathrm{ABG}$ & $\times$ \\
\hline $\mathrm{BG}$ & $\mathrm{BCG}$ & $\mathrm{AG}$ \\
\hline $\mathrm{CG}$ & $\mathrm{CAG}$ & $\times$ \\
\hline $\mathrm{AB}$ & $\mathrm{ABC}$ & $\mathrm{ABC}$ \\
\hline $\mathrm{BC}$ & $\mathrm{ABC}$ & $\mathrm{ABC}$ \\
\hline $\mathrm{CA}$ & $\mathrm{ABC}$ & $\mathrm{ABC}$ \\
\hline $\mathrm{ABG}$ & $\mathrm{ABG}$ & $\times$ \\
\hline $\mathrm{BCG}$ & $\mathrm{BCG}$ & $\times$ \\
\hline $\mathrm{CAG}$ & $\mathrm{CAG}$ & $\mathrm{ABC}$ \\
\hline $\mathrm{ABC}$ & $\mathrm{ABC}$ & $\mathrm{CAG}$ \\
\hline
\end{tabular}

Note: $\times$ indicates that the result of phase selection according to the phase selection process is not unique, and the fault phase cannot be accurately identified.

\section{Conclusions}

MMC adopts a positive sequence component control strategy during an asymmetric fault, and its negative sequence equivalent impedance is close to infinity, causing the positive and negative sequence current distribution coefficients of the MMC side protection to be no longer equal. Traditional Phase Selection Based On Variation Components and Phase Selection Based On Sequence Components are incorrect for this side. The preconditions of the phase are no longer satisfied, and the performance of the phase selection element is greatly reduced.

\section{References}

1. Xuan L, Qiang S, Wenhua L, et al. Fault ride-through control and its impacts on wind generators in a VSC-HVDC system[C]// IEEE International Symposium on Industrial 
Electronics. IEEE, 2013.

2. Jia K, Chen R, Xuan Z , et al. Fault Characteristics and Protection Adaptability Analysis in VSC-HVDC Connected Offshore Wind Farm Integration System[J]. IET Renewable Power Generation, 2018, 12(13):1547-1554.

3. Zhang J, Zhang B , Wang C . Improved schemes for traditional current-based phase selectors in wind power systems[J]. Generation, Transmission \& Distribution, IET, 2018, 12(21):5781-5788.

4. Beddard A , Barnes M . Modelling of MMC-HVDC Systems - An Overview[J]. Energy Procedia, 2015, 80:201-212. 